\title{
The Myth Of The Educated Manager Revisited
}

Craig M. Sasse, (E-mail: craig.sasse@rockhurst.edu), Rockhurst University

Ricard E. Downing, (E-mail: rick.downing@rockhurst.edu), Rockhurst University

James E. Puetz, (E-mail: james.puetz@rockhurst.edu), Rockhurst University

\begin{abstract}
In this work, we examine critical components of traditional education that seem to be the basis for the failure of management development. We differentiate teaching from learning and contend that effective management development should focus much more closely on experiential learning. Guidelines for identifying effective learning programs are provided. "The business schools seem to have forgotten the age-old definition of management-getting things done through people, not through analyses, not through probabilistic statistics, not through econometrics. Through people". (McGill, 1988, p. 167)
\end{abstract}

\section{INTRODUCTION}

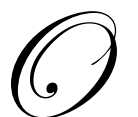

ver thirty years ago, Livingston (1970) authored a critique of management education. The thrust of Livingston's article, entitled "The Myth of the Well-Educated Manager," was that based on performance of managers who had educational pedigrees, management education was not delivering as promised. While the correlational evidence for some of his assertions was flawed, the claim that education programs were mostly ineffective in developing successful managers still holds a great deal of face validity. In 1994, three business academics at Case Western Reserve assessed the continuing criticisms of the educated managers, "MBA graduates vary tremendously but these criticisms have been made by too many different types of people (including employers, recruiters, alumni-MBAs themselves later in life, educators, administrators and parents) to be shared delusion” (Boyatzis et al., p. 4).

Since Livingston, others have critiqued management education. McGill (1988) devotes an entire chapter to critiquing the MBA, claiming, "MBAs have too little people sensitivity. Many seem to believe that good analytical skills coupled with knowledge of computers is sufficient. It is not" (157). He goes on to note that the aggressive individualism - where there is "a tendency not to suffer fools" - is rewarded in the academic setting where individuals are assessed under a competitive grade system. Boyatzis et al (1994) identify six commonly cited problems with MBA graduates. Among the reasons are an inability to work well in groups, an inability to communicate, an over orientation toward analytical versus action oriented modes, and exceedingly high expectations upon graduation. Management scholar, Mintzberg (2004), synthesized the critique with a comprehensive analysis of the MBA / management myth. He adds that management is experiential and that too many MBA students are the wrong people at the wrong time (either too inexperienced or unsuited for management work).

Business education is even derided by practitioners that pay a lot of money trying to develop their high potential managers. A recent Harvard Business Review article (2003) featured guest experts who were asked to comment on the hypothetical case of a director whose leadership training budget is slashed by $75 \%$. The expert responses are stinging. Noel Tichy, in his analysis, notes that he is proud he "got rid of almost every B school case study in GE's leadership development program” (p. 10). Susan Burnett (V.P. of Workforce Development at H-P) asserts that "Executives can no longer participate in five-to-ten-day programs and get only one or two days of value" (p. 8). A third expert, David Owens the Chief Knowledge Officer at Bausch \& Lomb wonders about any emphasis on classroom-based programs "which are a notoriously ineffective way of learning" (p. 11). Thus, the myth of the well educated manager remains 35 years after Livingston’s article. 
The need for superior general management has never been greater despite the widely-held belief that management education programs continue to fall short of providing the requisite knowledge, skills, and abilities. Bolt (1989) asserted that development of managers is more essential than ever before because "you can't run businesses like you did in the 1940s" (p. 4). Fundamentally, the heightened need for effective and timely management development at all levels reflects a need for managers to increasingly "work through others" (Bolt, 1989). Despite these shortcomings, business spends handsomely for management education. In addition to the over 100,000 MBAs matriculating each year, businesses spend four times as much on non-credit management and leadership development programs. So while companies may wonder about the cost of management development, they also understand that such development is vital to sustaining performance in an age where knowledge often trumps capital or other traditional competitive factors.

Finally, our understanding of learning has changed since Livingston's work was first published. In fact, the myth of the educated manager is quite predictable based on the learning research of the last thirty years. This article, after first exploring what we know about learning and how it is different from education, proposes some general guidelines for how managers can be developed more effectively so as to avoid the common problem of well-educated but ineffective managers.

\section{THE AGE OF LEARNING}

We now live in a knowledge age, replacing the industrial and information ages. A quick review of the ratio of tangible assets to market value provides evidence of the new knowledge age. For example, Microsoft Corporation's tangible assets make up a mere $1 \%$ of its total market capitalization; even old-line industrial firms like GE and IBM report only $14 \%$ and $23 \%$ in tangible assets, respectively (Kluge, Sten, \& Licht, 2001). There is now a premium for intellectual capital, or knowledge, which requires as its driving mechanism - learning.

Over the last twenty years the notion of learning has become preeminent in both management and education fields. Vaill (1991) introduced the idea of "permanent white water" as the metaphor for the work of the manager. Understanding and managing change has become the critical activity of the contemporary manager; and the one for which they are held most accountable. The most important skill for navigating the white water is learning. Vaill's subsequent book, Learning as a Way of Being (1996), asserts that the critical attribute of managers today is their ability to learn. The current business environment has spawned new terms such as knowledge management and real efforts by businesses to make knowledge creation and sharing an explicit, engineered process. Peter Senge and others have popularized the concept of systems learning or the learning organization. Knowledge should no longer be static or hoarded by a few people at the top of the hierarchy. Instead it must be diffused; the organization must be designed so it can continuously improve through learning. At the center of this process is the manager who must be a learner.

On a parallel track, education (including management education) has shifted—at least rhetorically—to a focus on learning. Educators Barr and Tagg (1995) introduced the "learning paradigm" to reflect a shift from a teaching emphasis to a learning emphasis. The gist of this paradigm shift is subtle but significant. Instead of focusing on what the instructor or curriculum "teaches" the emphasis should be on the learner and the facilitation of learning processes. It is a shift from what (content) to how (skills, process, and beliefs). Indeed, the latter emphasis is much more appropriate for those that must deal with permanent white water because knowing yesterday's answers (the teacher's prize) is not helpful for tomorrow's challenges.

If we are indeed in a knowledge age, then learning is the coin of the realm. In some ways management has become the nexus of the learning paradigm, as learning and development become keys to competitive advantage. Despite the calls from Vaill and others, management development is still mostly steeped in the old paradigm that honors teaching. The learning needs of business today and the paradigm of education have never been at greater odds. A fundamental understanding of how learning development differs from education can only help move institutions towards more effective management "education" programs. 


\section{LEARNING DEVELOPMENT VERSUS EDUCATION}

When Livingston wrote his critique, the learning research was seated predominantly in the domain of psychology; behaviorist theories such as conditioning and reinforcement were still prominent. But since 1970, research in the fields of cognitive psychology, education, anthropology, biology, and management has significantly advanced our understanding regarding the causes learning. This emerging understanding has exposed a gap between the notion of development (through learning) and education. This section will explore the differences between development and education.

\section{Education}

Societies since the days of the Greeks have been interested in educating adults. It is only recently (the last few hundred years or so) that the focus has shifted to teaching children, termed pedagogy (derived from Greek words of "ped" and "agogous" meaning child and leader of, respectively). The re-emergent field of adult education has spawned new insights into how adults are best educated. Knowles, Elwood, and Swanson (1998) summarize the subsequent synthesis of some important characteristics of adult learning (called andragogy) as contrasted with the more prevalent pedagogy traditions that govern education today (see table 1).

\begin{tabular}{|l|l|l|}
\hline \multicolumn{2}{|c|}{ Table 1. Contrast between Pedagogy and Androgogy (Knowles et al., 1998) } \\
\hline Dimension & Pedagogy & Andragogy \\
\hline Learner's Need to Know & What the teacher or curriculum decides & Know what and why they need to learn \\
\hline Learner's Self concept & Dependent Personality & Learner responsible for learning \\
\hline Role of Experience & Learner's experience of little worth & Rich experiences creates diversity \\
\hline Readiness to Learn & Readied by the Teacher & Based on need, just in time \\
\hline Learning Orientation & Subject-centered & Life or problem-centered \\
\hline Motivation & Extrinsic & Intrinsic \\
\hline
\end{tabular}

While education in the earliest of times used adult-centered techniques such as the Socratic Method, contemporary education has been built on pedagogical traditions. What is striking about the dichotomous nature of pedagogy and andragogy is that the labels from the table could easily be changed to "teaching" and "learning," respectively. Knowles et al. (1998) define education from a pedagogical orientation as well:

[Education] is an activity undertaken or initiated by one or more agents that is designed to effect changes in the knowledge, skill, and attitudes of individuals, groups, or communities. The term emphasizes the educator, the agent of change who presents stimuli and reinforcement for learning and designs activities to induce change. (p. 10-11).

Given this profile, management development based on an education model is bound to be problematic. While children should indeed be taught fundamental things like reading, managers must be learners. Vaill laments the misorientation of "institutional learning" as it relates to management education. Vaill (1996) asserts,

Perhaps most unfortunately of all, given today's need for learning strategies for permanent white water, some of the brightest and most energetic learners become superachievers within the criteria and assumptions of institutional learning. They read and remember more, and they do it faster. They orient their attention toward those who possess the expert knowledge and are not distracted by the learners who are not as comfortable. Some of these superachievers are largely free of negative fantasies about the system and do not fight it openly. They may exhibit creativity, sometimes of very high quality but almost always within the goals and objectives that are defined by the instructor and/or the traditions surrounding the subject matter. These high achievers who have accepted the institutional learning parameters are almost never outrageous or revolutionary in their work either in the way that they perform it or in its results (p. 40).

Institutional learning as Vaill calls it is steeped in the traditions of pedagogy. Livingston's original critique hits hard at the ability of pedagogy to address the unique developmental needs of managers. While an "education" 
might certainly prepare one with the personal qualities desired in managers, it is insufficient for developing management skills. As guided by the principles of andragogy, management learners are likely to be self-directed, intrinsically motivated, and likely to transform experience into useable knowledge. That must be the orientation for developing an "educated" manager.

\section{Learning}

In the emerging learning paradigm, the emphasis turns more to experience, application, and process. First, a definition of learning; table 2 provides some definitions, which all refer to the notion of change. In fact, development is all about change as it relates to the learner. And, management education must be especially sensitive to how it can effect change that results in different thinking and actions.

Table 2. Definitions of Learning

1. $\quad$ Learning involves change. It is concerned with the acquisition of habits, knowledge, and attitudes. (Crow \& Crow, 1963)

2. Learning is a change in the individual, due to the interaction of that individual, and his environment, which fills a need and makes him more capable of dealing adequately with his environment. (Burton, 1963)

3. Learning is essentially change due to experience. (Harris \& Schwann, 1961)

4. Learning is the process whereby knowledge is created through the transformation of experience. (Kolb, 1984)

It is well beyond the scope here to delve into the learning literature, spanning multiple disciplines, but it is helpful to understand two of the compelling features of learning: experience and emotion. It might be argued that learning starts and ends with experience. Experiential learning manifests itself in change. To the degree experiences can be transformed into meaningful knowledge, individuals are able to learn and ultimately change the way they think and behave. David Kolb's (1984) learning cycle and experiential learning theory captures this idea concretely. Specifically, the learning cycle is a structural representation of how the mind grasps experience and how it transforms that into knowledge. A key tenet of the learning cycle is that learning requires the learner to process through the cycle - which usually (but not always) starts with concrete experience.

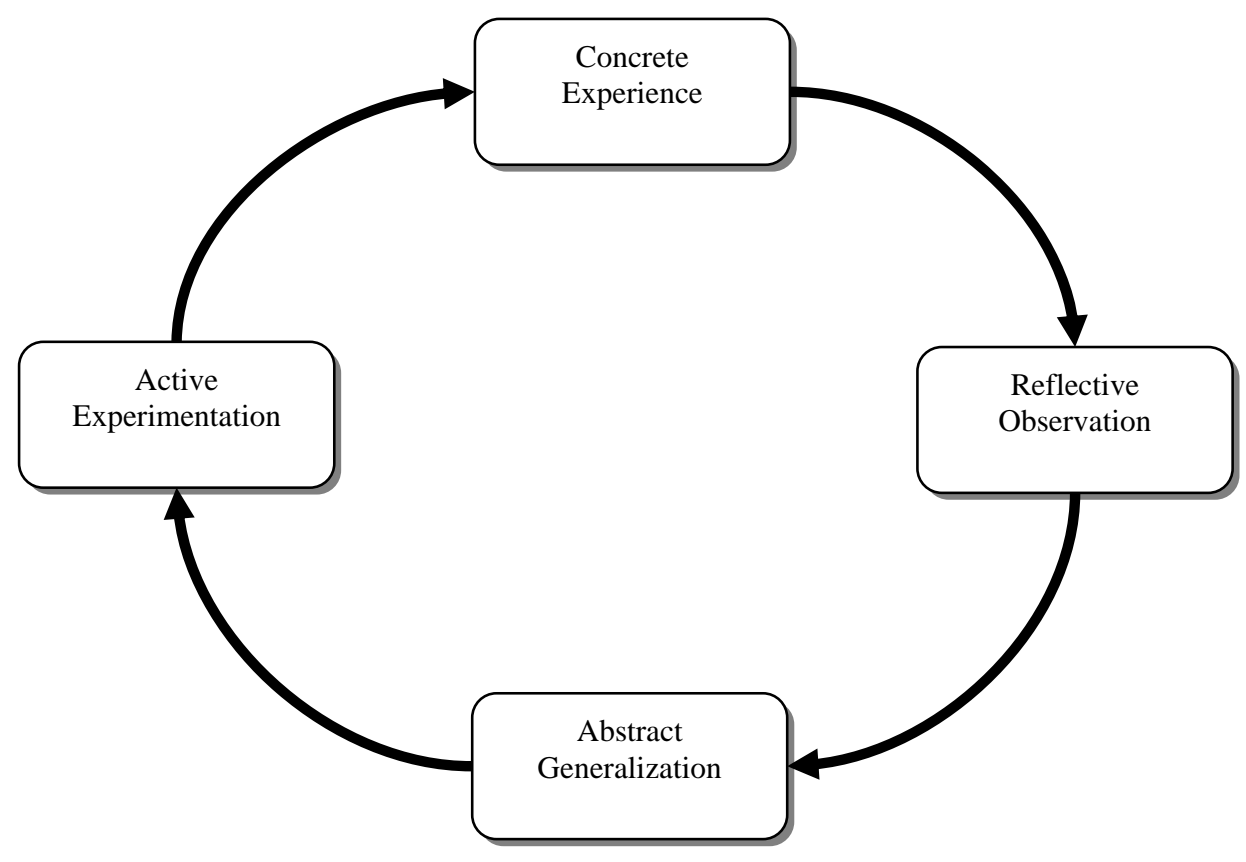

Figure 1: Kolb’s Learning Cycle. Adapted from Kolb (1984, p. 42) 
Learning is a process that is much bigger than simply memory, problem solving or creativity. Consider little children, their world is a treadmill that starts with a question that leads to a theory that is then tested and reflected on until the cycle starts anew. For change to occur the child can't just do, but she must think and reflect, else she is condemned to make the same mistakes again and again. Too often, education only deals with part of the wheel. For instance, school work can often focus on theory without evoking any actionable understanding of the concept, event, or phenomena. Says management scholar Charles Handy (1989), who articulates his own version of the cycle, "Learning is not measured by examinations, which usually only test the theory stage, but only by a growth experience, an experience understood and tested” (p. 63). ${ }^{1}$

Indeed an important part of the learning cycle is that learning must involve action. Kolb's active experimentation reflects this stage. Argyris's theory of action asserts that learning must be embedded in action. In fact, his first implication for action according to the theory is to "Design all learning to enhance effective action, not simply thought or insight. To test what you know is to produce what you claim you know" (Argyris, 1997, p. 12). Zull (2002) uses brain imaging studies to confirm the importance of active testing of understanding and hypotheses; it is this action step that gives meaning to experience and reflection.

While action and concrete experience are essential for learning, reflective processes provide for integration and sensory experiences to be comprehended and interpreted. Schön's notion of "reflective action" captures the dichotomous attributes of reflection versus action. The reflective practitioner captures the duality of living in the external real world (practitioner) but also moves inside to bring meaning and comprehension to that world. Reflection is about finding meaning and unity by assimilating new experiences into existing concepts ("rewiring" the neuronal networks). Zull (2002) states, "Reflection is a search for connections" (p. 167). We make this unity through images (and sometimes language). If we don’t have the image, we likely have no deep understanding.

While education typically focuses on cognition (knowledge), learning is a whole brain endeavor. Experience is never parsed into subjects or pieces of content. While memory is often difficult - try remembering those isolated pieces of information for a test - our minds recall much information without even trying. In fact, these remembered packets of information are anchored on experiences or events that have personal meaning. Most importantly, learning usually depends on non-cognitive aspects such as emotion and attitudes.

Biologist James Zull (2002) in his analysis of brain research notes the millions of neuronal connections that make the brain both facile and plastic. This latter concept has been well documented over the last couple of decades and reflects the ability of our minds to change these connections through experience. It is these neuronal networks that allow us to bring unity and meaning to disparate information - to see patterns, relationships, and meaning. (It is the back part of our brains that does this work and is related directly to the reflective observation capability of the human learner.)

The trump for all of this mental activity is emotion. Zull (2002) contends that "emotion may be more fundamental than cognition" in human learning (p. 57). People have very fast, reptilian parts of the brain that respond to fear, which can shut down learning - or lead the learner to assimilate experience into existing conceptual mindsets without the chance for reflection. In fact, knowledge is embedded in a complex of values and beliefs. These packets of know-how are called various names such as schemata or mindsets. Argyris (1997) calls them "learned theories," which include "underlying governing values" that are not easily changed (p. 10). Argyris asserts that double-loop learning (i.e., processing through the learning cycle to enact transformations) is necessary to change these mindsets ones that have embedded not just knowledge, but values and beliefs.

Brain research also shows an important relationship of emotions and feeling in the reflection process. That is, learners have to be emotionally involved to truly assimilate the new experiences with the old knowledge. In fact, learners tend to create and make connections with those things they care about and are passionate about. New ideas or

\footnotetext{
${ }^{1}$ Handy in a 1998 article for Change magazine states: "We learn by reflecting on what has happened. The process seldom works in reverse, although most educational programs assume that it does. We hope that we can teach people how to live before they live, or how to manage before they manage. Little of the teaching sticks” (p. 19).
} 
creations are not the thing of some spontaneous combustion; they come from what the person already knows or has. The implication for education is important: "most of the educational experiences seem too thin to make this type of impact. Students are exposed to several subjects each day, and the way they encounter these subjects often does not have much emotional impact” (Zull, p. 169). Desire activates the brain - especially that reflective part that must integrate and interpret - to find deep meaning, which can lead to significant change of the neuronal networks of the brain.

So learning, paradoxically, is quite natural and ongoing even while it is complicated by affective inputs and the need to engage in time-consuming and sometimes idiosyncratic transformative processes involving experience, reflection, and action. To the degree our mind can process experiences, engage prior knowledge through reflection, actively generate hypotheses and then test them out, the more likely we are going to learn by changing and developing our mindsets.

\section{ON-THE-JOB EXPERIENCE}

If we consider learning the preeminent role of the manager, authentic experience must be considered the best teacher. In their extensive study of managers and how they learned from their experience, McCall, Lombardo, and Morrison (1988) found five types of on-the-job authentic assignments that helped managers learn to manage. The first assignment cited by the large sample of managers was working on project or task forces. The learning thrust of these assignments was working with others and understanding their points of view. In fact, the managers learned to appreciate the value of subjective authority for people over whom they had no positional authority. They also were put in positions of being outside their technical mastery, requiring them to manage outside their narrow area of specialty.

The second assignment is line to staff switches. This helped the person learn to think beyond tactics and look at strategic issues. In this world, they had to live with ambiguity - with incomplete or imperfect information.

The next three assignments were the most powerful in that the person had full responsibility. These types of "developmental assignments carry with them the lessons of power and accountability" (p. 42). The first of these was starting something from scratch. Another one was fixing a business in trouble. Here they learned to work with people. The example is given of a manager who learned from an assignment about working with an existing, demoralized staff. Among other things, he learned how to use authority subjectively to improve performance. The young manager concluded, "The ultimate lesson was straightforward. You can tear things down by decree, but building them back up is another matter. Authority isn't much help in getting people to work together” (49).

While rich and potentially life changing, on-the-job experiential learning is also slow and inconsistent. McCall et al (1988) note that managers require 10-20 years to develop through experience. And, even this development is not assured because of the wide disparity in the type and quality of individual experiences. For example, the study revealed that managers learned most from high stakes job assignments rather than from comfortable ones that held marginal or no risk. But how many managers get the opportunity to cut their teeth on highstakes assignments - and have enough time to learn from their mistakes? Furthermore, McCall et al (1988) note that experiences are hard to manipulate in the work setting and can create imbalances that lead to negative consequences. Three potential confounds to the learning assignments include 1) personal confidence leads to arrogance; 2) toughness leads to insensitivity; and 3) independence leads to overmanaging.

\section{THE CASE OF MANAGEMENT}

For management the special challenge is that new skills and attitudes must be learned and developed, often quickly. McCall et al. (1988) describe this need well, "It would seem that talented people rather naturally practice and improve upon their existing skills. For management, however, the challenge is not just broadening specialist skills; it's building entirely new skills as the original strengths grow less relevant. As one looks at the lessons listed throughout this book, it's obvious that many of them are unique to the managerial job. Unless there is an as yet undiscovered chromosome, such skills must be developed” (p. 140). In 1980s dollars, McCall et al. (1988) estimate the cost of a failed manager is $\$ 500,000$ not counting the negative impact on revenue. 
Experience is a great teacher, but developing managers is a challenge because people cannot easily build on their specialist knowledge to become effective managers. As McCall et al. note, this is largely because becoming a manager requires fundamental change in not only knowledge but values and beliefs. For example, a successful salesperson often thrives on being controlling, independent, and ambitious. Such a value set, however, is not going to serve this person well going into management where the critical skill of the manager is to get things done through people.

Consider also the job of the manager involves some form of artistry, as Schön (1987) calls it. That is, the expertise of managers is often tacit and embedded in knowledge and actions that the manager cannot easily describe or explain. The use of tacit knowledge governs the manager - called "knowing-in-action" by Schön (1987). This knowing by action can become automatic and largely unarticulated by the practitioner. Schön (1987) notes, however, another phenomena of "reflection-in-action," which takes place when something unexpected occurs, where our existing schema or mindset comes up against experience it has not addressed (or what normally works does not work in this case). This causes reflection, which leads to the type of dialectic that Kolb describes with the learning cycle or Argyris with double-loop learning.

The mindsets that define excellent managers cannot be taught because these mindsets are much more than simply knowledge. Experience must be combined with reflection and action to develop these managerial mindsets. While institutional learning may be somewhat effective in teaching some specialist skills ${ }^{2}$, if it has a pedagogical orientation it results in the problems cited by Livingston. Schön (1987) like McGill questions even the penultimate business pedagogy, the case method, "Critics internal and external to the business schools now question the adequacy of the hallowed case method to the specific demands of management in particular industries as well as to the more general demands of responsible stewardship and management under conditions of uncertainty” (pp. 14-15).

The manager's work is in thinking and taking action according to situational factors. The situation is permanent white water - dealing with contextual factors that involve objects, things, and people. Pedagogical education will not provide the required learning because the learning involves values and beliefs (non-cognitive aspects) that are developed through practice. New managers are often condemned to repeat mistakes not just because of lack of knowledge, but for how they perceive events and interpret them in the first place. For example, if a manager concludes that a mistake by an employee calls for stricter control over that employee, the manager is operating under a mindset (or theory-in-use as Argyris calls it) that workers' actions must be controlled. That is, the manager places importance on controlling behavior rather than developing and trusting managerial systems that allow workers to perform while becoming co-participants with the managers. And this value remains tacit and unchallenged unless significant learning (i.e., change of mindset) occurs.

\section{DEVELOPING EFFECTIVE MANAGERS}

So, the myth of the educated manager and the ongoing complaints about the performance of educated managers is quite predictable. Using a classroom (or any other venue) for pedagogical learning will not develop professional managers. But must we be condemned to rely simply on the unpredictable and slow progression of onthe-job learning?

While management education programs, such as the MBA, are largely ineffective for management development, on-the-job experience is usually insufficient, or unnecessarily long, as well. One of the conclusions of McCall et al (1988) was that simply going through life or having experience is not enough to become an effective manager. It is what is done with those experiences to develop the mindsets specific to management that matters. Among the findings from McCall's study was that the executive's ability to dig deep for meaning - that is, loop through the learning cycle - was critical in making the set of experiences learning ones. Furthermore, they had a learning orientation, one where they were in charge instead of a boss or a teacher. McCall et al. (1988) conclude,

\footnotetext{
${ }^{2}$ It is doubtful that pedagogical learning is very effective in effecting learning in specialist areas either. Brown, Collins, and Duguid (1989) asserted the ideas of situated cognition and communities of practice as necessary conditions for learning expertise in any field-professional or craft. These practitioners (e.g., accountants) "are bound by intricate, socially constructed webs of belief, which are essential to understanding what they do" (33).
} 
"Overwhelmingly, their [the managers who learned] motivation for seeking change was to do something challenging, intriguing, exciting, broadening - not just to get promoted at all costs” (131).

The key is to facilitate learning opportunities, not to educate managers. That is, we cannot expect that educational methods will result in fundamental development of managerial skill and ability. Learning theory, especially that which has been revealed over the past thirty years, says so. Instead, we must design learning programs that expose learners' mindsets to critical knowledge, values, and beliefs associated with management skill. And to provide them a combination of experience, reflection, and testing that allows them to develop and change how they think. In fact, if done correctly, learning programs that apply holistic learning theory (e.g., the learning cycle) offer the promise of getting the most out of experience and development. The learning manager can be real rather than myth.

Thus, developing managers need both experience and focused learning programs. Executives should look for several things in helping their high potential managers develop by using both on the job experience and appropriate learning programs. In setting job assignments, executives can assist development by:

- $\quad$ Creating opportunities of responsibility that require working through people (and this does not require the manager be given direct reports).

- $\quad$ Encouraging action and creating some slack so that small mistakes can be opportunities for learning.

- $\quad$ Giving the developing manager time to get away for focused development; time to think and reflect and to develop essential skills related to identifying opportunity and working through people to exploit that opportunity.

Here is what to look for in learning programs:

- $\quad$ The learning is situated in contexts that require the learner to do management. In both Kolb and Handy's learning models, action and reflection are necessary. Ideally, this action is in a context that places the learner in doing the work of management, not just talking about it. This can be simulated as long as it engages the learner in similar management processes. The advantage of learning programs - if facilitated well - is that mistakes can lead to learning.

- $\quad$ There is a process context to the learning as instructors are focused on behavior and underlying thinking, not just delivering content and assessing knowledge of content. You can determine whether a program is process-oriented

- $\quad$ There is rigor in the learning process. That is, the learner must work though frustrations and unexpected barriers in the context of the learning problem. Expect some frustration from the learner as good learning programs tease out conflict with attitudes (i.e., underlying values and beliefs about management work).

- $\quad$ There is an expectation the learning will be applied to their real work. One of Mintzberg's criticisms of current management development is that it involves the wrong people at the wrong time. People that are too early in their career or not yet in managerial positions, will be dealing with abstractions that cannot be applied. It is the working context that makes the learning worthwhile. Also, ideally some accountability is placed on applying what is learned.

The need for effective general management is too great for companies to wait 15 years for its new managers to become professionals. Effective developmental programs, provided they incorporate learning, rather than education, modalities offer the best hope for fulfilling the promise of "educated managers." 


\section{REFERENCES}

1. Argyris, C. (1997, Feb.). Learning and teaching: A theory of action perspective. Journal of Management Education, 21(1) pg. 9-26.

2. Barr, R. and J. Tagg. (1995, Nov/Dec). From teaching to learning-A new paradigm for undergraduate education. Change, 27, p. 12-25.

3. Bolt, J.E. (1989). Executive Development: A Strategy for Corporate Competitiveness. Harper Row.

4. Boyatzis, R., Cowen, S., \& Kolb, D. (1994). Innovation in Professional Education: Steps on a Journey from Teaching to Learning. Jossey-Bass.

5. Brown, J.S., Collins, A., \& Duguid, P. (1989, Jan-Feb). Situated cognition and the culture of learning. Educational Researcher, 32-42.

6. Burton, W. H. (1963). Basic Principles in a Good Teaching-Learning Situation. In L. D. Crow \& A. Crow (Eds.), Readings in Human Learning (pp. 7-19). New York: McKay.

7. $\quad$ Crow, L.A. \& Crow, A. (1963) Readings in Human Learning, New York: McKay.

8. Handy, C. (1989). The Age of Unreason. Harvard Business School Press.

9. Handy, C. (1998, Sept/Oct). A Proper Education. Change, 13-19.

10. Harris, T.L. \& Schwann, W.E. (1961). Selected readings on the learning process. New York: Oxford University Press.

11. Kesner, I.F. (2003, May). Leadership development: Perk or priority? Harvard Business Review.

12. Kluge, J, W. Stein, \& T. Licht. (2001). Knowledge Unplugged. Palgrave.

13. Knowles, M.S., Holton III, E.F., \& Swanson, R.A. (1998). The Adult Learner, (5 ${ }^{\text {th }}$ Ed.). Gulf Publishing Company.

14. Kolb, D.A. (1984). Experiential Learning. Prentice Hall.

15. Livingston, J.S. (1971, January-February). Myth of the well-educated manager. Harvard Business Review.

16. McCall, Jr., M.W., M.M. Lombardo, \& A.M. Morrison. (1988). The Lessons of Experience: How Successful Executives Develop on the Job. Lexington Books.

17. McGill, M.E. (1988). American Business and the Quick Fix. Henry Holt and Company.

18. Mintzberg, H. (2004). Managers Not MBAs. Berrett-Koehler Publishers, Inc.

19. Schön, D.A. (1987). Educating the Reflective Practitioner. Jossey-Bass.

20. Vaill, P.B. (1991). Managing as a Performing Art: New Ideas for a World of Chaotic Change. Jossey-Bass.

21. Vaill, P.B. (1996). Learning as a Way of Being. Jossey-Bass.

22. Zull, J.E. (2002). The Art of Changing the Brain. Stylus. 


\section{NOTES}

